\title{
Hypertrophic obstructive cardiomyopathy Effects of acute and chronic verapamil treatment on left ventricular systolic and diastolic function
}

\author{
DAVID M ANDERSON, GILBERT L RAFF, THOMAS A PORTS, BRUCE H BRUNDAGE, \\ WILLIAM W PARMLEY, KANU CHATTERJEE \\ From the Division of Cardiology and the Cardiovascular Research Institute, University of California, San Francisco, \\ Califormia, USA
}

SUMMARY Changes in left ventricular systolic and diastolic function and outflow gradient were evaluated in patients with obstructive hypertrophic cardiomyopathy after intravenous acute treatment with verapamil (15 patients) and after six months of oral chronic treatment (11 patients). All patients had severe symptoms despite beta blockade, and the condition of all but two improved appreciably after chronic treatment with verapamil. Resting left ventricular outflow tract gradient decreased in six of 15 patients after intravenous verapamil, and in five of 11 patients after long term treatment, but there was no change in provocable gradients nor any correlation between changes in gradient and improvement in symptoms. Left ventricular ejection rate did not change after intravenous or oral treatment. End systolic pressure/end systolic volume index remained unchanged after oral verapamil treatment. Whereas left ventricular total stroke volume index and end diastolic volume index increased without any significant change in left ventricular end diastolic pressure, indicating improved left ventricular diastolic function. In some patients the left ventricular diastolic pressure-volume curve shifted downwards or to the right or both.

These findings suggest that improvement in symptoms with verapamil in patients with obstructive hypertrophic cardiomyopathy is unlikely to be related to changes in left ventricular outflow gradient or in systolic function and may be related to improved diastolic function.

Pharmacological treatment for the symptoms of hypertrophic cardiomyopathy has relied on the use of beta blocking agents. In many patients, however, symptoms persist despite adequate-beta blockade..$^{1-4}$ Recently, the slow channel inhibiting agents (calcium antagonists) verapamil and nifedipine have been shown to improve symptoms in patients with hypertrophic cardiomyopathy. ${ }^{5-7}$ Amelioration of dyspnoea, chest pain, and presýncope and improved exercise tolerance have been reported. Favourable haemodynamic responses such as the reduction of left ventricular outflow pressure gradient and increased

Requests for reprints to Dr Kanu Chatterjee, Department of Medicine, School of Medicine, University of California, Moffitt 1186, San Francisco, California 94143, USA.

Accepted for publication 29 November 1983 cardiac output have been noted after intravenous treatment with verapamil or nifedipine. Left ventricular function during exercise has also improved after relatively short term oral treatment with verapamil. ${ }^{8}$ Only limited information is, however, available on the influence of long term treatment with slow channel inhibiting agents on left ventricular systolic or diastolic function. In this study we used catheterisation and angiography to evaluate changes in left ventricular function after treatment with intravenous verapamil and after six months of oral treatment in patients with obstructive hypertrophic cardiomyopathy who had symptoms despite adequate beta blockade.

Patients and methods

STUDY POPULATION

Fifteen patients (11 men and four women; age range 
15-74 (mean 52) years) with clinical, echocardiographic, haemodynamic, and angiographic findings typical of hypertrophic obstructive cardiomyopathy were studied. No patient had coronary artery disease, primary valve disease, or hypertension. All had been treated previously for variable periods with the beta blocker propranolol at a mean dose of $370 \mathrm{mg} /$ day. Thirteen of 15 patients continued to have chest pain, dyspnoea, or presyncope and were therefore considered for treatment with verapamil. The remaining two patients had intolerable side effects with propranolol. The study was approved by the Committee on Human Research, and each patient gave written informed consent. No complications occurred during any of the studies.

\section{STUDY DESIGN}

On entry to the study each patient was interviewed to assess the severity of symptoms. Chest pain and dyspnoea were graded according to the New York Heart Association classification, and the presence or absence of syncope or presyncope were noted. The standard 12 lead electrocardiograms were reviewed and the degree of left ventricular hypertrophy assessed according to the Sokolow index.9 Treatment with propranolol was discontinued at least $\mathbf{4 8}$ hours before cardiac catheterisation.

All 15 patients underwent initial cardiac catheterisation by the femoral approach. Right heart catheterisation was performed with a triple lumen balloon flotation catheter to determine right atrial, pulmonary arterial, and pulmonary capillary wedge pressures, and cardiac output was determined in triplicate by the thermodilution technique with the same catheter.

Left ventricular pressure was measured with a No 5 French or No 6 French micromanometer tip Millar catheter and a No 7 French fluid filler pigtail catheter attached to a strain gauge transducer. The Millar catheter was calibrated externally with a mercury reference and matched simultaneously with the pressure recorded from the pigtail catheter. In two patients the Millar catheter could not be positioned within the left ventricle.

In each patient left ventricular outflow pressure gradient was determined from the simultaneous measurement of aortic root and left ventricular cavity pressures. The pressure gradient was determined both at rest and after provocation with a ventricular extrasystole, amyl nitrite, and the Valsalva manoeuvre. Biplane cineventriculography was then performed in the right anterior and left anterior oblique projections at 60 frames/s film speed, while left ventricular pressure was recorded simultaneously with the Millar catheter. All patients were then given verapamil intravenously. In the initial seven patients a 10 mg bolus was given. The remaining eight patients received intravenous verapamil according to the protocol of Rosing et $\mathrm{al}^{6}:$ a $0.1 \mathrm{mg} / \mathrm{kg}$ bolus was followed by a $0.007 \mathrm{mg} / \mathrm{kg} / \mathrm{min}$ infusion for five minutes; a second $0.1 \mathrm{mg} / \mathrm{kg}$ bolus by a $0.014 \mathrm{mg} / \mathrm{kg} / \mathrm{min}$ infusion for five minutes; and a third $0.1 \mathrm{mg} / \mathrm{kg}$ bolus by a $0.021 \mathrm{mg} / \mathrm{kg} / \mathrm{min}$ infusion for five minutes. In no patient was it necessary to stop the intravenous infusion because of severe hypotension or atrioventricular block.

Repeat resting and provocable outflow pressure gradients were determined, and ventriculography was performed with the same dose of contrast at least 20 minutes after the initial ventriculogram.

Oral treatment with verapamil was then given to 12 of the 15 patients and the dose varied from 80 to 240 $\mathrm{mg}$ three to four times daily (average $690 \mathrm{mg} /$ day) depending on the clinical response. After six months of treatment 11 patients agreed to be re-evaluated by cardiac catheterisation. Haemodynamic measurements and ventriculograms were performed by the identical protocol as that used in the initial study about two to three hours after the last oral dose of verapamil. Clinical evaluation was performed at intervals independently by one of us during long term treatment.

Derived haemodynamic indices were calculated as follows: stroke volume index $\left(\mathrm{ml} / \mathrm{m}^{2}\right)=\mathrm{CO} / \mathrm{HR} / \mathrm{BSA}$ where $\mathrm{CO}$ is cardiac output, $\mathrm{HR}$ is heart rate/minute and BSA is body surface area. Systemic vascular resistance (dyn $\left.\mathrm{s} \mathrm{cm}^{-5}\right)=(M A P-R A P) /$ $C O \times 80$, where $M A P$ is mean arterial pressure and RAP is mean right atrial pressure. Pulmonary vascular resistance (dyn $\left.\mathrm{s} \mathrm{cm}^{-5}\right)=($ MPAP-PCW)/ CO $\times 80$, where MPAP is mean pulmonary artery pressure, and PCW is mean pulmonary capillary wedge pressure.

Frame by frame analysis of the ventriculograms was performed for at least one entire cardiac cycle. The left ventricular cavity outline was traced from each frame in both projections with a digitising light pen that interfaced directly with a PDP $11 / 70$ computer. Left ventricular volumes were then calculated by the modified Simpson's method. A left ventricular volume curve was constructed, and left ventricular end diastolic and end systolic volumes, ejection fraction, and mean normalised ejection rate were calculated. Ejection fraction was calculated as (LVEDVLVESV)/LVEDV where LVEDV and LVESV are left ventricular end diastolic and end systolic volume respectively. Mean normalised systolic ejection rate $(\mathrm{ml} / \mathrm{min} / \mathrm{ml})$ was calculated as (LVEDV-LVESV)/ (LVEDV $\times$ ET), where ET is systolic ejection time determined by the time (in seconds) between aortic valve opening and closing.

By synchronising intraventricular pressure and volume throughout the cardiac cycle pressure volume 


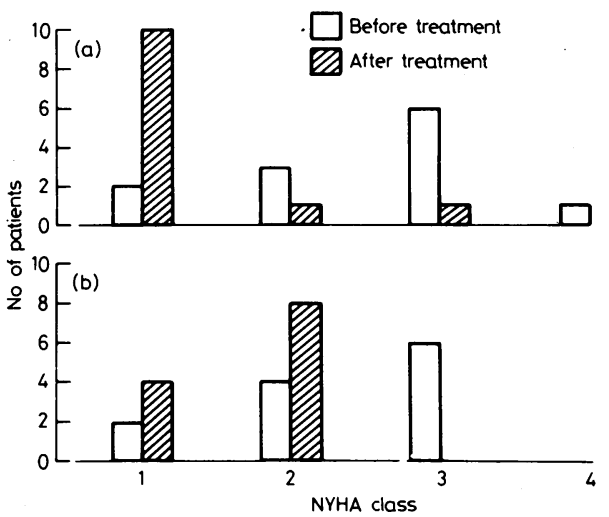

Fig. 1 Clinical response by New York Heart Association classification to six months of oral treatment with verapamil in (a. patients with chest pain and (b) patients with dyspnoea.

loops were constructed in 12 patients in whom the data were adequate for analysis. In 13 patients the ratio of the left ventricular pressure to volume at end systole (at the time of aortic valve closure) was determined to assess changes in contractility before and after acute and chronic treatment with verapamil.

\section{Results}

\section{CLINICAL RESPONSE}

No adverse effects occurred after intravenous verapamil. Similarly, in no patient was it necessary to discontinue oral treatment because of any undesirable effects or deterioration in clinical status. The clinical response to oral treatment is shown in Fig. 1. Ten of the 12 patients who received maintenance treatment for six months had had severe episodic chest pain despite propranolol treatment; after oral treatment with verapamil, however, only two continued to have chest pain. Ten patients had dyspnoea before verapamil treatment and in all 10 this symptom was

Table 1 Mean ( $\pm S E M)$ haemodynamic values after acute intravenous and chronic oral treatment with verapamil

\begin{tabular}{|c|c|c|c|}
\hline & \multicolumn{3}{|l|}{ Treatment } \\
\hline & $\begin{array}{l}\text { Before } \\
(n=15)\end{array}$ & $\begin{array}{l}\text { Acute } \\
(n=13)\end{array}$ & $\begin{array}{l}\text { Chromic } \\
(n=11)\end{array}$ \\
\hline \multirow{6}{*}{$\begin{array}{l}\text { Heart rate (beat/min) } \\
\text { Mean arterial pressure } \\
\text { (mm Hg) } \\
\text { Systemic vascular resistance } \\
\text { (dyn } \mathrm{cm}^{-5} \text { ) } \\
\text { Cardiac index }\left(1 / \mathrm{min} / \mathrm{m}^{2} \text { ) }\right. \\
\text { Left ventricular end diastolic } \\
\text { pressure (mm } \mathrm{Hg}_{\mathrm{g}} \text { ) } \\
\text { Resting outflow tract gradient } \\
\text { (mm Hg) } \\
\text { Provocable outflow tract } \\
\text { gradient (mm Hg) }\end{array}$} & $76 \pm 19$ & $72 \pm 18$ & $67 \pm 18$ \\
\hline & $92 \pm 12$ & $82 \pm 13^{\star}$ & $88 \pm 12$ \\
\hline & $\begin{array}{l}1502 \pm 301 \\
2.39 \pm 0.45\end{array}$ & $\begin{array}{l}1285 \pm 341 \\
2.54 \pm 0.59\end{array}$ & $\begin{array}{l}1386 \pm 240 \\
2 \cdot 4 \pm 0.32\end{array}$ \\
\hline & $14 \pm 5$ & $21 \pm 8$ & $15 \pm 5.6$ \\
\hline & $57 \pm 43$ & $49 \pm 41$ & $34 \pm 40$ \\
\hline & $114 \pm 60$ & $106 \pm 64$ & $85 \pm 66$ \\
\hline
\end{tabular}

${ }^{\star} \mathrm{p}<0.02$. appreciably improved (at least by one NYHA class) during treatment.

Although in some patients the voltage of the QRS complex in the precordial electrocardiographic leads decreased, in the group as a whole there was no appreciable change in the Sokolow index after chronic oral treatment.

\section{HAEMODYNAMIC EFFECTS}

Acute intravenous verapamil caused a statistically significant decrease in mean $( \pm S D)$ arterial pressure from $92 \pm 12$ to $82 \pm 13 \mathrm{~mm} \mathrm{Hg}$ (Table 1). Systemic vascular resistance tended to decrease and cardiac index to increase, although these changes were not statistically significant. Heart rate and end diastolic pressure did not change significantly. In all 15 patients a left ventricular outflow pressure gradient was present at rest before verapamil treatment. In six patients the resting gradient decreased after intravenous verapamil, whereas in the remaining nine there was either an increase or no change in the resting gradient. In the group as a whole there was no significant change in the mean resting or provocable gradient after intravenous verapamil.

In 11 of 12 patients the haemodynamic effects of chronic oral treatment with verapamil could be assessed. Though heart rate tended to be slower during chronic treatment, the mean changes were not statistically significant. There was no significant change in mean arterial pressure, systemic vascular resistance, cardiac index, or left ventricular end diastolic pressure after chronic treatment. Similarly, there was no change in pulmonary capillary wedge pressure, mean pulmonary artery pressure, right atrial pressure, or pulmonary vascular resistance. Changes in resting and provocable left ventricular outflow gradients after chronic treatment could be assessed in 11 patients, and there was a variable response. In five patients the resting gradient decreased, and in the remaining six there was no change. In the group as a whole neither the mean resting nor the provocable gradient changed significantly after chronic treatment. There was also no correlation between changes in left ventricular outflow gradient and improvement in symptoms.

\section{CHANGES IN SYSTOLIC FUNCTION}

Changes in ejection fraction, mean normalised systemic ejection rate, end systolic pressure to end systolic volume ratio, and stroke volume index were determined in 13 patients after intravenous verapamil and in 11 patients after six months of oral treatment (Table 2). After intravenous verapamil, there was no significant change in ejection fraction, mean normalised systemic ejection rate, or stroke volume index; however, end systolic pressure to end systolic volume ratio decreased slightly but significantly (from 
Table 2 Changes in systolic function after acute intravenous and chronic oral treatment with verapamil (figures are means $\pm S E M)$.

\begin{tabular}{llll}
\hline & \multicolumn{3}{l}{ Treatment } \\
\cline { 2 - 4 } & Before & Acute & Chronic \\
\hline Ejection fraction (\%) & $73 \pm 8$ & $72 \pm 9$ & $73 \pm 9$ \\
$\begin{array}{l}\text { End systolic pressure : volume } \\
\text { ratio }\end{array}$ & $2 \cdot 6 \pm 0.79$ & $2 \cdot 15 \pm 0.7 \star$ & $2 \cdot 28 \pm 1 \cdot 2$ \\
$\begin{array}{l}\text { Mean normalised systemic } \\
\text { ejection rate/s }\end{array}$ & $2 \cdot 3 \pm 0.3$ & $2 \cdot 72 \pm 0.84$ & $2 \cdot 32 \pm 0.23$ \\
Stroke volume index $\left(\mathrm{ml} / \mathrm{m}^{2}\right)$ & $69 \pm 19$ & $64 \pm 14$ & $81 \pm 11^{\star}$ \\
\hline
\end{tabular}

${ }^{\star} \mathrm{p}<0.02$.

$2.6 \pm 0.79$ to $2.15 \pm 0.7, p>0.02$ ). After chronic treatment ejection fraction and mean normalised systemic ejection rate remained unchanged, and the decrease in end systolic pressure to end systolic volume ratio seen after intravenous verapamil was not significant after chronic treatment. Angiographic stroke volume index did increase significantly from 62 to $81 \mathrm{ml} / \mathrm{m}^{2}$. Thus there was no significant change in left ventricular contractile function after chronic treatment.

\section{CHANGES IN DIASTOLIC FUNCTION}

After intravenous verapamil there was no significant change either in end diastolic volume or in end diastolic pressure. In general, after intravenous verapamil treatment there was no change in the diastolic pressure-volume curve.

After chronic treatment there was an increase in end diastolic volume in seven of the 10 patients in whom these data were available. In the remaining three, there was no change. In the group as a whole
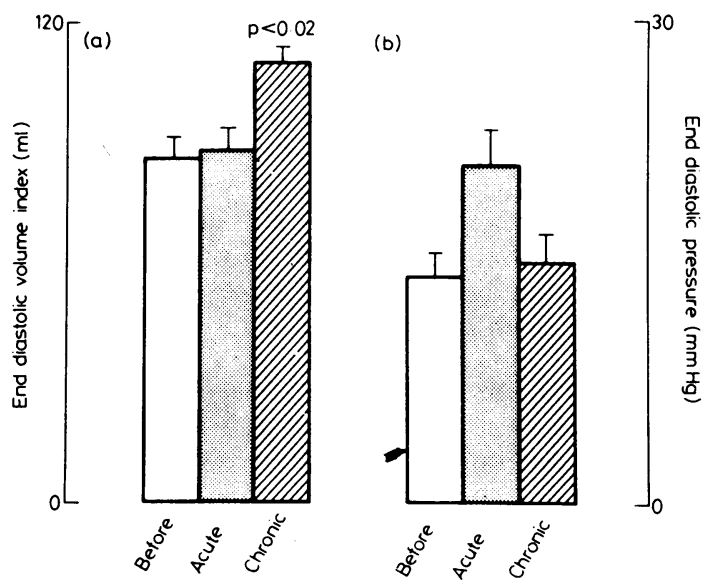

Fig. 2 (a) Mean ( $\pm S E M)$ end diastolic volume index and (b) mean $( \pm S E M)$ left ventricular end diastolic pressure before and after acute and after chronic oral treatment with verapamil. The increase in volume without a significant change in pressure after chronic treatment suggests an increase in ventricular compliance.
Anderson, Raff, Ports, Brundage, Parmley, Chatterjee
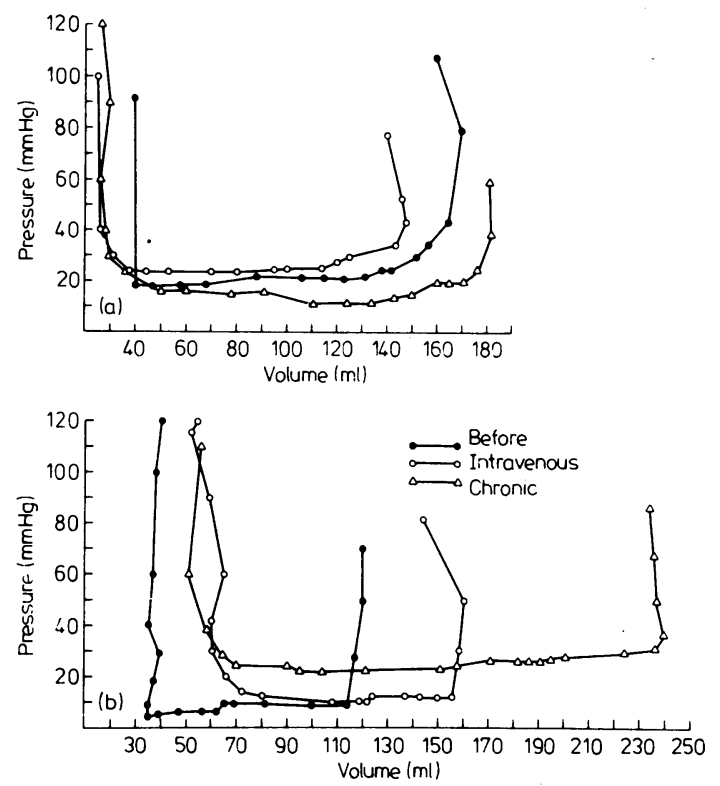

Fig. 3 Diastolic pressure-volume curves in two patients before and after intravenous and after chronic oral treatment with verapamil. (a) In one patient a shift in the curve to the right and downwards indicates a clearcut change in compliance after chronic treatment. (b) The curve in this patient was shifted to the right but at a higher diastolic pressure.

there was a significant increase in end diastolic volume index from $86 \pm 18$ to $110 \pm 13(p<0.02)$. Changes in end diastolic pressure were variable, but the mean left ventricular end diastolic pressure did not change (Fig. 2). In four patients the diastolic pressure-volume curve shifted to the right or downwards and to the right; in one patient no obvious change occurred, and in two there was a shift upwards and to the left (Fig. $3)$.

\section{Discussion}

The results of the present study confirm that many patients with hypertrophic cardiomyopathy derive relief of symptoms from chronic treatment with verapamil. The patients in this study had symptoms despite taking relatively large doses of propranolol, and in most patients dyspnoea, chest pain, and presyncope improved after oral treatment with verapamil. We did not find any adverse reactions in our patients, although these have been reported by others. ${ }^{10}$

The role of outflow obstruction in the origin of symptoms remains controversial. ${ }^{11}$ Dyspnoea, chest pain, and presyncope frequently occur with exertion. All the patients in this study had haemodynamic features of left ventricular outflow obstruction before 
treatment with verapamil. Though the resting outflow pressure gradient tended to be lower after chronic treatment, the provocable gradient remained unchanged. The fact that in individual patients improvement in symptoms did not correlate with the change in provocable gradient (akin to the exercise induced gradient) after treatment suggests that factors other than obstruction to outflow are responsible for them. This impression is substantiated by the finding that subgroups of patients with hypertrophic cardiomyopathy both with and without outflow obstruction have similar symptoms. ${ }^{11}$

The characteristic hypercontractility and cavity obliteration in these patients has also been implicated in causing symptoms. In this study there was no deterioration in left ventricular pump function after either acute or chronic treatment. There was no significant decrease in left ventricular ejection fraction or mean normalised systolic ejection rate. Indeed, after chronic treatment, left ventricular stroke volume increased without any significant change in left ventricular end diastolic pressure, indicating improved left ventricular pump function. Improvement in left ventricular pump function has been reported also during exercise after chronic treatment with verapamil. ${ }^{12}$

Recently, it has been suggested that the changes in the ratio of the end systolic pressure to end systolic volume reflect the changes in ventricular contractility. ${ }^{13}$ In our patients left ventricular pressure was determined with a micromanometer catheter, and left ventricular volumes were calculated by biplane cineangiography. Thus these methods should allow reliable determination of the end systolic pressure to volume ratio. Although the ratio of end systolic pressure to volume declined after intravenous verapamil-indicating a depression of contractile function-this index of contractility remained unchanged after chronic treatment.

Left ventricular contractile function and afterload are the major determinants of the mean normalised systolic ejection rate. In our patients changes in left ventricular wall stress (afterload) were not calculated. After chronic treatment, however, end diastolic volume increased without any significant change in intraventricular pressure, indicating that, if anything, there was an increase in wall stress. Such an increase in afterload should decrease mean normalised systemic ejection rate. If contractile function were also depressed a further decrease in normalised ejection rate would be expected. Thus a lack of any change in the mean normalised ejection rate strongly suggests that there was no decrease in contractile function after chronic treatment. Radioisotope angiographic studies have also shown unaltered left ventricular ejection fraction or ejection rate. ${ }^{14}$

In seven of 10 patients in this study left ventricular end diastolic volume increased significantly after chronic treatment. One of the remaining three patients had severe mitral regurgitation before treatment, and mitral regurgitation decreased appreciably after chronic treatment. A reduction in mitral regurgitation might explain the lack of increase in end diastolic volume in this patient. In the study by Kaltenbach et al left ventricular end diastolic volume increased in six of 10 patients after chronic treatment. ${ }^{5}$ Hanrath et al found an increase in left ventricular dimension by echocardiography in most of their patients treated long term. ${ }^{15}$ Thus chronic treatment with verapamil appears to cause ventricular dilatation and a larger end diastolic volume in patients with hypertrophic cardiomyopathy.

The mechanisms for the increase in end diastolic volume are not entirely clear. Fluid retention and increased intravascular volume may be associated with increased intracardiac volumes. None of our patients, however, gained weight or developed peripheral oedema. Systemic venous pressure also remained unchanged. Although heart rate tended to be slower after chronic treatment, the degree of change in rate was not great enough to explain the significant increase in end diastolic volume. Decreased contractile function or increased resistance to left ventricular ejection cannot explain the increase in end diastolic volume in our patients, as the indices of contractile function and systemic vascular resistance were unchanged after chronic treatment.

Increased left ventricular diastolic compliance is another potential mechanism which can cause an increase in left ventricular end diastolic volume with a concomitant increase in stroke volume. The end diastolic pressure in our patients did not increase significantly after chronic treatment. Increased end diastolic volume with an increase in end diastolic pressure strongly suggests increased left ventricular diastolic compliance. We attempted to evaluate changes in left ventricular compliance from the shifts in the diastolic pressure-volume curve. After chronic treatment there was a shift to the right or to the right and downwards in the diastolic pressure-volume curve in four to seven patients, indicating increased diastolic compliance.

The limitations of contrast angiographic techniques in determining left ventricular volume in patients with hypertrophic cardiomyopathy must be considered. When frame by frame analysis of the contrast ventriculogram is performed it is often difficult to detect slight changes in the left ventricular silhouette from one frame to another. Accurate detection of such changes, however, is necessary for changes in diastolic compliance to be determined precisely from the shift in left ventricular pressure-volume curves. Nevertheless, this study suggests that diastolic compliance 
can improve in some patients after chronic treatment. Lorell et al also noted a shift downwards and to the right in the diastolic pressure dimension curves after treatment with nifedipine-another slow channel entry blocking agent-in some patients with hypertrophic cardiomyopathy. ${ }^{16}$

The mechanism for the improved diastolic compliance in some patients receiving chronic treatment with verapamil remains unclear. We did not determine changes in intrapericardial pressures or right ventricular volumes. Thus the influence of verapamil on ventricular interaction resulting from the pericardial restraining effect contributing to the changes in left ventricular diastolic pressure-volume relations remains unknown. Improved left ventricular relaxation may be a potential mechanism for the improved diastolic compliance. In a number of studies several indices of left ventricular relaxation were determined, and an improvement in the relaxation properties was reported after treatment with verapamil in patients with hypertrophic cardiomyopathy..$^{74-16}$ Though in the present study changes in left ventricular relaxation were not assessed, it is possible that improved relaxation contributed to the improved diastolic compliance in some of our patients.

Kaltenbach et al noted a decrease in left ventricular thickness by contrast ventriculography, ${ }^{5}$ which may partly explain the increased end diastolic volume after chronic treatment with verapamil. In patients with hypertrophic cardiomyopathy, however, the distribution of hypertrophy is usually non-uniform, ${ }^{17}$ and therefore the accurate determination of the mean wall thickness necessary to calculate left ventricular mass is not feasible in these patients. Hence we did not attempt to assess changes in left ventricular hypertrophy after chronic treatment. Echocardiographic studies have shown conflicting results as to whether wall thickness diminishes with long term treatment. ${ }^{18} 19$ Thus the influence of verapamil on left ventricular hypertrophy remains unclear. Though we did not observe any appreciable adverse effects during chronic treatment, hypotension and pulmonary oedema may be precipitated in some patients at the start of treatment. 1020 Decreased contractile function during acute treatment, as occurred in the present study, might help to explain such undesirable effects.

In conclusion, the results of the present study suggest that chronic treatment with verapamil is associated with improvement in symptoms in most patients with hypertrophic cardiomyopathy. Changes in left ventricular outflow gradient appear to be inconsequential. Left ventricular systolic function remains unchanged during chronic treatment and cannot be related to the improvement in symptoms. Improved diastolic function might explain the relief of some of the symptoms after chronic treatment.
This work was supported in part by a grant in aid from Don and Susan Schleicker.

\section{References}

1 Harrison DC, Braunwald E, Glick G, Mason DT, Chidsey CA, Ross J Jr. Effects of beta adrenergic blockade on the circulation with particular reference to observations in patients with hypertrophic subaortic stenosis. Circulation 1964; 29: 84-98.

2 Edwards RHT, Kristinsson A, Warrell DA, Goodwin $\mathrm{JF}$. Effects of propranolol on response to exercise in hypertrophic obstructive cardiomyopathy. $\mathrm{Br}$ Heart $\mathrm{f}$ 1970; 32: 219-25.

3 Frank MJ, Abdulla AM, Canedo MI, Saylors RE. Long-term medical management of hypertrophic obstructive cardiomyopathy. Am $\mathcal{F}$ Cardiol 1978; 42: 9931001.

4 Hubner PJB, Ziady GM, Lane GK, et al. Double-blind trial of propranolol and practolol in hypertrophic cardiomyopathy. Br Heart F 1973; 35: 1116-23.

5 Kaltenbach M, Hopf R, Kober G, Bussmann W-D, Keller M, Petersen $Y$. Treatment of hypertrophic obstructive cardiomyopathy with verapamil. Br Heart $\mathcal{F}$ 1979; 42: $35-42$.

6 Rosing DR, Kent KM, Borer JS, Seides SF, Maron BJ, Epstein SE. Verapamil therapy: a new approach to the pharmacologic treatment of hypertrophic cardiomyopathy. I. Hemodynamic effects. Circulation 1979; 60: 1201-7.

7 Lorell BH, Paulus WJ, Grossman W, Wynne J, Cohn PF, Braunwald E. Improved diastolic function and systolic performance in hypertrophic cardiomyopathy after nifedipine. $N$ Engl f Med 1980; 303: 801-3.

8 Rosing DR, Kent KM, Maron BJ, Epstein SE. Verapamil therapy: a new approach to the pharmacologic treatment of hypertrophic cardiomyopathy. II. Effects on exercise capacity and symptomatic status. Circulation 1979; 60: 1208-13.

9 Grubschmidt HA, Sokolow M. The reliability of high voltage of the $Q R S$ complex as a diagnostic sign of left ventricular hypertrophy in adults. Am Heart $\mathcal{F}$ 1957; 54: 689-94.

10 Epstein SE, Rosing DR. Verapamil: its potential for causing serious complications in patients with hypertrophic cardiomyopathy. Circulation 1981; 64: 437-41.

11 Chatterjee K, Raff G, Anderson D, Parmley WW. Hypertrophic cardiomyopathy: therapy with slow channel inhibiting agents. Prog Cardiovasc Dis 1982; 25: 193-210.

12 Hanrath P, Schlüter M, Sonntag F, Diemert J, Bleifeld W. Influence of verapamil therapy on left ventricular performance at rest and during exercise in hypertrophic cardiomyopathy. Am $\mathcal{F}$ Cardiol 1983; 52: 544-8.

13 Sagawa K, Suga H, Shoukas AA, Bakalar KM. Endsystolic pressure/volume ratio: a new index of ventricular contractility. Am $\mathcal{F}$ Cardiol 1977; 40: 748-53.

14 Bonow RO, Rosing DR, Bacharach SL, et al. Effects of verapamil on left ventricular systolic function and diastolic filling in patients with hypertrophic cardiomyopathy. Circulation 1981; 64: 787-96. 
15 Hanrath P, Mathey DG, Kremer P, Sonntag F, Bleifeld W. Effect of verapamil on left ventricular isovolumic relaxation time and regional left ventricular filling in hypertrophic cardiomyopathy. Am $\mathcal{F}$ Cardiol 1980; 45: 1258-64.

16 Lorell BH, Paulus WJ, Grossman W, Wynne J, Cohn PF. Modification of abnormal left ventricular diastolic properties by nifedipine in patients with hypertrophic cardiomyopathy. Circulation 1982; 65: 499-507.

17 Maron BJ, Gottdiener JS, Epstein SE. Patterns and significance of the distribution of left ventricular hypertrophy in hypertrophic cardiomyopathy: a wide angle, two dimensional echocardiographic study of 125 patients. Am F Cardiol 1981; 48: 418-28.

18 Troesch M, Hirzel HO, Jenni R, Krayenbühl HP. Reduction of septal thickness following verapamil in patients with asymmetric septal hypertrophy (ASH) [Abstract]. Circulation 1979; 59 (suppl II): 155.

19 Rosing DR, Condit JR, Maron BJ, et al. Verapamil therapy: a new approach to the pharmacologic treatment of hypertrophic cardiomyopathy: III, Effects of longterm administration. Am $\mathcal{F}$ Cardiol 1981; 48: 545-53.

20 McKenna WJ, Harris L, Perez G, Krikler DM, Oakley C, Goodwin JF. Arrhythmia in hypertrophic cardiomyopathy. II. Comparison of amiodarone and verapamil in treatment. Br Heart $\mathcal{F}$ 1981; 46: 173-8. 